NASA Technical Memorandum 102567

\title{
Computational Simulation of Damping in Composite Structures
}

D.A. Saravanos and C.C. Chamis

Lewis Research Center.

Cleveland, Ohio

Prepared for the

2nd National Congress in Mechanics

Athens, Greece, June 29-July 1, 1989

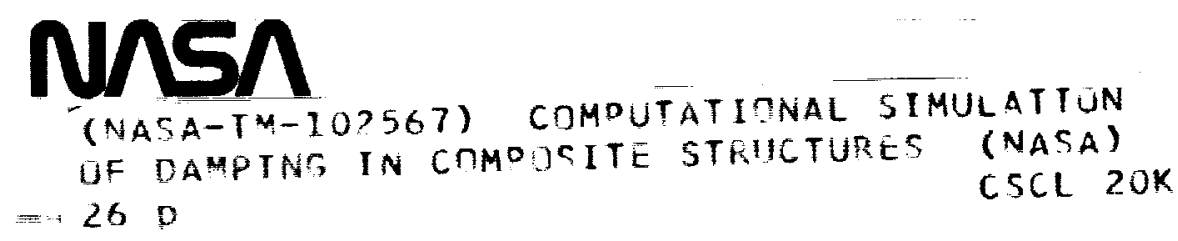

(NASA-TM-10?567) COMDUTATIONAL SIMULATHUN
OF DAMPING IN COMOOCITE STRHCTURES (NASA)
CSCL 2OK

N9O-20432 $=26 \quad 0$ 
$i=\ldots$

$-1-2=$

$=-\therefore=-2=-$ 


\title{
COMPUTATIONAL SIMULATION OF DAMPING IN COMPOSITE STRUCTURES
}

\author{
D.A. Saravanos* and C.C. Chamis * \\ National Aeronautics and Space Administration \\ Lewis Research Center \\ Cleveland, Ohio 44135
}

\begin{abstract}
A computational methodology is developed for the prediction of passive damping in composite structures. The method involves multiple levels of damping modelling by integrating micromechanics, laminate, and structural damping theories. The effects of temperature and moisture on structural damping are included. The simulation of damping in the structural level is accomplished with finite-element discretization. Applications are performed on graphite/epoxy composite beams, plates, and shells to illustrate the methodology. Additional parametric studies demonstrate the variation of structural modal damping with respect to ply angles, fiber volume ratio, and temperature.
\end{abstract}

\section{NOMENCLATURE}

$\begin{array}{ll}A & \text { Area. } \\ {\left[A_{d}\right]} & 3 \times 3 \text { extensional laminate damping matrix. } \\ {\left[A_{s}\right]} & 3 \times 3 \text { extensional laminate stiffness matrix. } \\ {[B]} & \text { Strain shape function matrix. } \\ {[C]} & \text { Global damping matrix. } \\ {\left[C_{d}\right]} & 3 \times 3 \text { coupling laminate damping matrix. } \\ {\left[C_{s}\right]} & 3 \times 3 \text { coupling laminate stiffness matrix. } \\ {\left[D_{d}\right]} & 3 \times 3 \text { flexural laminate damping matrix. } \\ {[D s]} & 3 \times 3 \text { flexural laminate stiffness matrix. } \\ E & \text { Normal modulus. } \\ \mathbf{f} \dagger & \text { Force. } \\ \mathbf{F} & \text { Discretized force. } \\ G & \text { Shear modulus. }\end{array}$

*National Research Council - NASA Research Associate at Lewis Research Center. **Senior Research Scientist.

†Bold characters indicate vectors. 


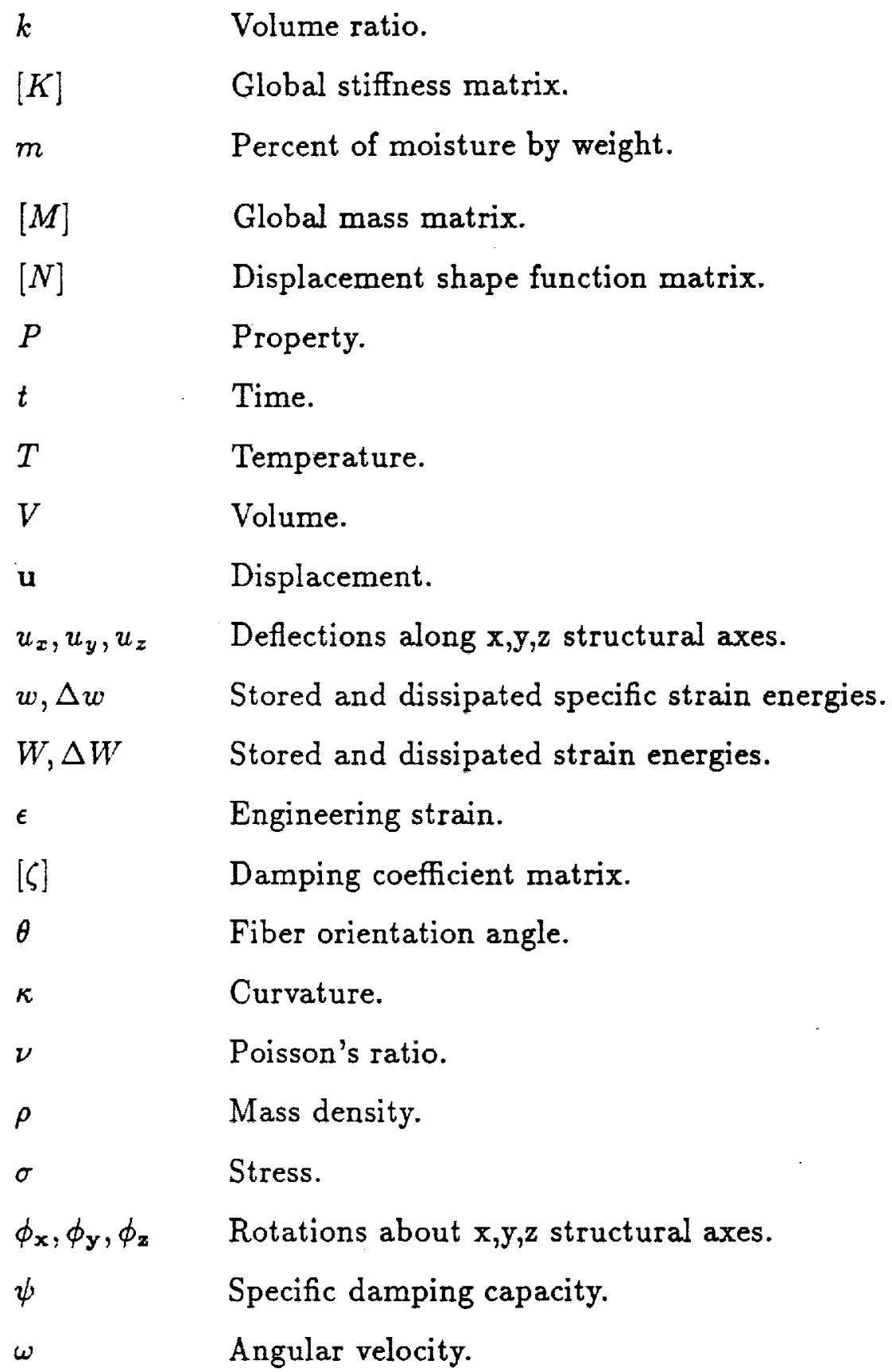

\section{Subscripts}

$\begin{array}{ll}a & \text { Dynamic amplitude. } \\ b & \text { Field force. } \\ c & \text { Ply (off-axis) } \\ d & \text { Damping. } \\ e & \text { Finite element. } \\ f & \text { Fiber. }\end{array}$




$\begin{array}{ll}g d & \text { Glass transition, dry. } \\ g w & \text { Glass transition, wet. } \\ i & \text { Node. } \\ l & \text { Ply (on-axis). } \\ L & \text { Laminate. } \\ m & \text { Matrix. } \\ M & \text { Mechanical. } \\ n & \text { n-th vibration mode. } \\ o & \text { Reference. } \\ t & \text { Surface traction. }\end{array}$

\section{Superscripts}

o

Laminate mid-plane.

\section{Direction}

Normal longitudinal.

22

Normal in-plane transverse.

12

Shear in-plane.

$n$

Normal.

$s$

Shear.

\section{INTRODUCTION}

The significance of damping to the dynamic performance of structures is broadly recognized. Passive damping is a significant dynamic parameter for vibration and sound control, fatigue endurance, and impact resistance. However, present light-weight and highperformance requirements imposed on most structural applications restrict the use of many traditional non-structural damping sources. It is desirable, therefore, to use materials which combine high damping in addition to other favorable mechanical properties. Fiber reinforced polymer- matrix composites are known to exhibit material damping one or two orders higher than most common metals as a result of the high damping of polymer matrices and the material heterogeneity. Composites are already preferred in many structural 
applications due to their high specific stiffness and strength, hence, the option of passive structural damping is an added advantage to these advanced materials. Recent work on the damping of unidirectional composites [1] and composite laminates [2] has shown that composite damping depends on an array of micromechanics and laminate parameters, including constituent material properties, fiber volume ratios, ply angles, ply thicknesses, ply stacking sequence, temperature, moisture, and existing damage. Composite damping is also anisotropic, but exhibits an opposite anisotropy trend than stiffness and strength, being minimum in the direction of the fibers and maximum in the transverse direction and in shear. It is apparent, therefore, that in order to realize significant structural benefits from the damping of composite materials, integrated structural mechanics theories should be formulated correlating the damping of composite structures to parameters of the basic constituent materials, laminate configuration, hygro-thermal conditions, and structural geometry.

Unified mechanics theories are available for many elastic properties [3] required for the prediction of the undamped dynamic response of composite structures. However, it seems that an integrated methodology for predicting the damping of composite structures, and their damped dynamic response, needs yet to be developed. Reported research on the subject is mostly limited to the damping of unidirectional composites and laminates. Analytical and experimental studies on the damping of continuous unidirectional fiber composites have been reported [4-6]. These studies mostly assumed nondissipative fibers, were restricted to longitudinal and in-plane shear damping, and overlooked the anisotropic fiber damping properties. Theoretical and experimental work for the damping in discontinuous fiber composites is presented in refs. 7-9. The damping of off-axis composites and symmetric laminates has been investigated [7,9-12]. Work on the structural damping of symmetric composite plates has been also reported $[13,14]$.

In this paper, an integrated finite-element based method is developed for simulating the damping of composite structures. In contrast to the limitations of other methods $[13,14]$, the present methodology is applicable to both plate and shell-type structures and 
general laminate configurations. It includes damping due to flexure (bending and torsion), in-plane extension, and extension-flexure coupling. Furthermore, the method includes the effects of temperature, moisture, micro-damage, and interlaminar matrix layers on structural damping. A specialty triangular plate element has been developed for the direct formulation of finite element damping matrices based on micromechanics and laminate damping theories. An additional feature of the method is the capability to calculate the modal damping capacities of composite structures. Applications of the method are focused on composite beams, plates, and shells. In this manner, the effect of structural geometry on the structural composite damping is illustrated. Moreover, parametric studies illustrate the effect of fiber volume ratio (FVR), ply angles, and operating temperature on structural composite damping.

\section{METHOD}

In this section an integrated theory for simulating structural composite damping is briefly described. The on-axis damping of each composite material (damping along the material axes) is synthesized from the constituent fiber/matrix properties and fiber volume ratios (FVR's). Then, the damping capacities of off-axis composites are calculated and, subsequently, the local laminate damping capacity is formulated. Finite element discretization is utilized for the assembly of the global damping matrix and/or the calculation of modal structural damping. Analogous approaches are utilized for other mechanical properties [3].

\section{Damped Dynamic Response}

Application of the principle of virtual work to an elastic structure under dynamic loading requires that the work of discrete forces, body forces, and surface tractions during an infinitesimal virtual displacement should be equal to the sum of strain energy and dissipated strain energy variations,

$$
\delta \mathbf{u}_{\mathbf{i}}^{\mathbf{T}} \mathbf{F}_{\mathbf{i}}+\int_{V} \delta \mathbf{u}^{\mathbf{T}} \mathbf{f}_{\mathrm{b}} d V+\int_{V} \delta \mathbf{u}^{\mathbf{T}}(-\rho \ddot{\mathbf{u}}) d V+\int_{A} \delta \mathbf{u}_{\mathbf{t}}^{\mathbf{T}} \mathbf{f}_{\mathbf{t}} d A=\int_{V} \delta \epsilon^{\mathbf{T}} \sigma d V+\int_{V} \delta(\Delta w) d V
$$


where, $\delta \mathbf{u}_{i}^{\mathbf{T}} \mathbf{F}_{\mathbf{i}}$ is the virtual work of discrete forces, $\delta \mathbf{u}^{\mathbf{T}} \mathbf{f}_{\mathbf{b}}$ the virtual work of non-inertial body forces per unit volume, $\delta \mathbf{u}^{\mathbf{T}}(-\rho \ddot{\mathbf{u}})$ the virtual work of inertial body forces per unit volume, $\delta \mathbf{u}_{\mathfrak{t}}^{\mathbf{T}} \mathbf{f}_{\mathbf{t}}$ the virtual work of surface tractions per unit area, $\delta \epsilon^{\mathbf{T}} \sigma$ the variation of specific strain energy, and $\delta(\Delta w)$ the dissipated specific strain energy during the virtual motion.

The virtual dissipated strain energy in eq. (1) depends on the viscoelastic behavior of the material. Assuming a Voigt type of solid, the virtual dissipated strain energy is express as,

$$
\delta(\Delta W)=\int_{V} \delta \epsilon^{\mathbf{T}}[\zeta] \dot{\epsilon} d V
$$

By combining eqs. (1-2) and applying a finite element discretization scheme $\mathbf{a}=[N] \mathbf{u}$ and $\epsilon=[B] \mathrm{u}$, eq. (1) results in a system of discrete dynamic equations:

$$
\begin{aligned}
{[M] \ddot{\mathbf{u}}+[C] \dot{\mathbf{u}} } & +[K] \mathbf{u}=\mathbf{F}_{\mathbf{i}}+\mathbf{F}_{\mathbf{b}}+\mathbf{F}_{\mathbf{t}} \\
{[M] } & =\int_{V}[N]^{T} \rho[N] d V \\
{[C] } & =\int_{V}[B]^{T}[\zeta][B] d V \\
{[K] } & =\int_{V}[B]^{T}[E][B] d V
\end{aligned}
$$

where, $[N]$ and $[B]$ are the displacement and strain shape functions respectively. In the previous equations, $[E]$ and $[\zeta]$ represent the local stiffness and damping coefficient matrices of the material respectively. In the case of plate/shell composite structures, $[E]$ and $[\zeta]$ represent the local laminate stiffness and damping matrices $\left[E_{L}\right]$ and $\left[\zeta_{L}\right]$ respectively.

\section{Laminate Damping}

Based on eq. (2), integration over a complete vibration cycle provides the specific dissipated strain energy per cycle $\Delta w$,

$$
\Delta w=\oint \delta \epsilon^{\mathbf{T}}[\zeta] \dot{\epsilon}
$$


For sinusoidal vibration, $\epsilon=\epsilon_{\mathbf{a}} \sin (\omega t)$, the previous equation yields,

$$
\Delta w=\pi \omega \epsilon_{\mathbf{a}}^{\mathbf{T}}[\zeta] \epsilon_{\mathbf{a}}
$$

In the case of composite laminates, the generalized strain $\epsilon_{L}$ represents the midplane strain and curvature vector,

$$
\epsilon_{\mathbf{L}, \mathbf{a}}=\left\{\epsilon^{\circ}, \mathbf{k}\right\}
$$

and in accordance with eq. (6) the dissipated strain energy per cycle per unit area is:

$$
\Delta w_{L}=\pi \omega \epsilon_{\mathbf{L}, \mathbf{a}}^{\mathbf{T}}\left[\zeta_{L}\right] \epsilon_{\mathbf{L}, \mathbf{a}}
$$

As shown in ref. 2, The dissipated strain energy of a laminate is also expressed in terms of the damping matrices $\left[A_{d}\right],\left[C_{d}\right]$, and $\left[D_{d}\right]$.

$$
\Delta w_{L}=\frac{1}{2} \epsilon_{\mathbf{L}, \mathbf{a}} T\left[\begin{array}{ll}
{\left[A_{d}\right]} & {\left[C_{d}\right]} \\
{\left[C_{d}\right]} & {\left[D_{d}\right]}
\end{array}\right] \epsilon_{\mathbf{L}, \mathbf{a}}
$$

In the previous equation, the extensional damping matrix $\left[A_{d}\right]$ is associated with extensional deformations, the flexural damping matrix $\left[D_{d}\right]$ is associated with bending and torsional deformations, and the extension-flexure coupling damping matrix $\left[C_{d}\right]$ is associated with coupled extension-flexure deformations. All three matrices in eq. (9) are fully populated. The damping matrices depend on the off- axis SDC's of the individual plies and the laminate configuration. They also include the interlaminar damping contributions of the interply matrix layer, which have shown to be a significant additional source of damping in composite laminates [2]. The damping coefficient matrix $\left[\zeta_{L}\right]$ is expressed in terms of the previous damping matrices by combining eqs. (8) and (9),

Ref. 1 describes the micromechanics theory for the damping of composite plies. The off-axis composite damping is related to the on-axis elastic and dissipative properties and fiber orientation. The off-axis damping matrix $\left[\psi_{c}\right]$ is fully populated due to in-plane coupling between extension and shear. The on-axis SDC's depend on the hysteretic damping and the elastic properties of the matrix and fibers, the fiber volume ratio, and the interfacial friction damping from broken/debonded fibers. 


\section{Hygrothermal Effect}

Temperature and moisture primarily affect the properties of the polymer matrix including damping, as a result, many properties of composites are sensitive to hygrothermal variations. In this manner, temperature and moisture may have a definite effect on the response of composite structures. Previous studies [15] have shown that the hygro-thermal effect on most mechanical properties of the matrix can be expressed as,

$$
\frac{P_{M}}{P_{o}}=\left[\frac{T_{g w}-T}{T_{g d}-T_{o}}\right]^{0.5}
$$

Based on the fact that for temperature ranges below the glass transition the matrix damping is increasing with temperature, an inverted form of equation (10) has been proposed for the hygro-thermal effect on the matrix damping [1]:

$$
\frac{P_{d}}{P_{\mathrm{o}}}=\left[\frac{T_{g d}-T_{o}}{T_{g w}-T}\right]^{q}
$$

The wet glass transition temperature is [15],

$$
T_{g w}=T_{g d}\left(0.005 m_{l}^{2}-0.1 m_{l}+1\right)
$$

The exponent $q$ in eq. (11) can be correlated to experimental damping data of each individual polymer matrix. In the present study, the value $q=0.5$ is assumed. The effects of temperature and moisture on structural damping are simulated based on the previously described micromechanics, laminate, and structural damping theories. A similar approach is used for other mechanical properties.

\section{Structural Modal Damping}

Since the elasto-dynamic response of any structure, undergoing small deflections, is a linear combination of individual vibration modes, structural damping associated with each mode would provide a natural and meaningful measure regarding the overall damping capacity of the composite structure. In the remaining sections, the global damping capacity of the structure for a particular mode will be identified as structural modal damping. 
Thus, an array of modal damping factors is generated, each one representing the damping capacity of the structure vibrating solely at the respective mode shape. The modal specific damping capacity (SDC) associated with the $\mathrm{n}$-th vibration mode $\psi_{n}$ is:

$$
\psi_{n}=\frac{\int_{V} \Delta w_{n} d V}{\int_{V} w_{n} d V}
$$

where $\Delta w_{n}$ and $w_{n}$ represent the dissipated and maximum specific modal strain energies per cycle. For the case of plate/shell composite structures the structural modal damping becomes,

$$
\psi_{n}=\frac{\int_{A} \Delta w_{L n} d A}{\int_{A} w_{L n} d A}
$$

where $\Delta w_{L n}$ and $w_{L n}$ are respectively the dissipated and maximum laminate modal strain energies of the $\mathrm{n}$-th mode, as defined in eq. (9).

The integrations in eq. (14) are performed numerically using finite element discretization. Such a finite element scheme has been developed for a triangular plate element with 3 nodes, 6 degrees of freedom per node $u_{i}=\left\{u_{x}, u_{y}, u_{z}, \phi_{x}, \phi_{y}, \phi_{z}\right\}$, linear shape functions for membrane deflections, and cubic shape functions for flexure.

Integration is first performed over the area of the triangular finite element. The damping and maximum strain energies per cycle, over the area of the triangular element $A_{e}$ would be respectively:

$$
\begin{gathered}
\Delta W_{e, n}=\frac{1}{2} \int_{A_{e}} \mathrm{u}_{\mathrm{e}, \mathrm{n}}{ }^{T}\left[B_{e}\right]^{T}\left[\begin{array}{ll}
{\left[A_{d}\right]} & {\left[C_{d}\right]} \\
{\left[C_{d}\right]} & {\left[D_{d}\right]}
\end{array}\right]\left[B_{e}\right] \mathrm{u}_{\mathrm{e}, \mathrm{n}} d A_{e} \\
W_{e, n}=\frac{1}{2} \int_{A_{e}} \mathrm{u}_{\mathrm{e}, \mathrm{n}}{ }^{T}\left[B_{e}\right]^{T}\left[\begin{array}{ll}
{\left[A_{s}\right]} & {\left[C_{s}\right]} \\
{\left[C_{s}\right]} & {\left[D_{s}\right]}
\end{array}\right]\left[B_{e}\right] \mathrm{u}_{\mathrm{e}, \mathrm{n}} d A_{e}
\end{gathered}
$$

where $\left[A_{s}\right],\left[C_{s}\right]$, and $\left[D_{s}\right]$, are the extensional, coupling, and flexural laminate stiffness matrices. $\left[B_{e}\right]$ is the element strain shape function matrix, and $u_{e, n}$ is the nodal displacement vector of the respective mode. Both integrals are calculated numerically using three-point quadrature. The modal SDC of the $\mathrm{n}$-th mode $\psi_{n}$ is assembled according to eq. (14):

$$
\psi_{n}=\frac{\sum_{j=1}^{N_{e}}\left(\Delta W_{e, n}\right)_{j}}{\sum_{j=1}^{N_{e}}\left(W_{e, n}\right)_{j}}
$$


For lightly damped systems with nonclustered natural frequencies, as may be the case of most composite structures, use of the undamped modes of eq. (3) will provide sufficient accuracy. In this case, the direct solution of the damped dynamic system (3) may be substituted by a less computationally intensive scheme of modal superposition.

\section{APPIICATIONS AND DISCUSSION}

Modal damping capacities of three different composite structures were simulated to illustrate the present methodology. The three structures were: (1) a composite beam $16 \mathrm{in}$ long, 2 in wide, 0.2 in thick (in some cases 0.08 in thick); (2) a square plate 16 in long, 16 in wide, 0.2 in thick; and (3) a cylindrical shell panel 16in long, 16 in wide, 10in in radius, and 0.2 in thick. These three typical structural components were selected in order to demonstrate the effect of structural configuration on the modal SDC's. The structural complexity increases from Structure 1 (beam) to Structure 3 (shell). All structures were assumed fabricated from the same composite system of high-modulus surface treated graphite (HM-S) fiber in an epoxy matrix. The mechanical properties of this composite system are shown in Table 1. The composite system was selected to match the 0.50 FVR HM-S/DX210 graphite/epoxy composite for which experimental damping data values are available [16]. The damping properties of the fiber and matrix for this composite system were backcalculated from measured on-axis SDC's based on the micromechanics damping theory in ref. 1. The dry glass transition temperature of the matrix was taken to be $215^{\circ} \mathrm{C}\left(420^{\circ} \mathrm{F}\right)$. Each structure was modeled using a finite element mesh of 55 nodes and 80 triangular plate elements. Undamped mode shapes were used in the formation of structural modal SDC's

The SDC of the first mode of the composite beam in free-free support with a symmetric $(\theta / 90+\theta / 45+\theta /-45+\theta)$ s laminate configuration is shown in Fig. 1 as a function of the outer ply fiber orientation angle $\theta$ with respect to axial beam direction. Each ply was 0.010 in thick. The predictions correlate very well with measured damping values reported in ref. 16. The measurements were performed on composite beams vibrating at their first mode (first bending) in a nearly free-free configuration. The experiments were conducted in 
order to measure the flexural SDC of the composite laminate, however, the measured damping was actually structural modal damping. The predicted laminate SDC based on the laminate damping theory reported in ref. 2, is also plotted in Fig. 1. The predicted values for both structural and local laminate damping are very close, illustrating that testing of composite beams in free- free support will provide good estimations of passive laminate damping.

Additional parametric studies were conducted regarding the effect of material and environmental parameters on structural damping. Due to the space limitation, the studies were restricted on the effect of FVR, fiber orientation angle, and operating temperature $T$ on the modal SDC's of the previously described structures in cantilever support (Fig. 2). The laminate configuration in the latter cases was a symmetric angle-ply $\left(( \pm \theta)_{5}\right)_{s}$ with 20 plies through the thickness, each $0.010 \mathrm{in}$ thick. In all parametric studies, one parameter was varying and the remaining two were held fixed at the following nominal values: 0.50 FVR, $\pm 45^{\circ}$ ply angles, and room temperature $\left(21.1^{\circ} \mathrm{C}\left(70^{\circ} \mathrm{F}\right)\right)$.

\section{Cantilever Beam}

The first four modal SDC's and natural frequencies of the 0.50 FVR HM- S/Epoxy cantilever beam at room temperature are plotted in Fig. 3. The symbols indicate the simulation points. As seen in Fig. 3, only the 1st modal SDC exhibits uniform variation with $\theta$. Mode 1 was always the 1 st bending mode of the beam. The SDC is rapidly increasing with the ply angle and follows the trend of the flexural laminate SDC [2]. However, the SDC's of the three higher modes vary irregularly as the ply angles increase from 0 to 90 degrees. The variation of the anisotropy of the composite laminate and the dependence of laminate properties on the fiber orientation angle, have caused the higher modes to switch shape between out-of-plane bending, torsion, and in-plane bending/shear. For example, mode 2 at $0^{\circ}$ is the 1 st torsional mode, and mode 3 is the 2 nd bending. Near $15^{\circ}$ both modes have equal frequencies and switch shapes. Similar switchings in modal shapes occur between the $3 \mathrm{rd}$ and 4 th mode. Mode 3 at $0^{\circ}$ is the 2 nd out-of-plane bending, then subsequently switches to the 1st torsion, to the 1st in-plane bending, to the 
3 rd out-of-plane bending, and finally to the 1 st in-plane bending. Mode 4 at $0^{\circ}$ is the 1 st in-plane bending, and then switches to the 1st torsion, the 3rd bending, the 1 st in-plane bending, and the $3 \mathrm{rd}$ bending respectively.

As seen in Fig. 3, at double natural frequencies the respective modal SDC's change rapidly. This happens because the modes switch shapes, therefore, the strains and stresses associated with modal SDC's also change near the double natural frequencies resulting in the observed damping variations. The out-of-plane 1st, 2nd, and $3 \mathrm{rd}$ bending modes follow similar trends to the laminate flexural SDC, but they have different values for ply angles between $15^{\circ}$ and $70^{\circ}$ due to transverse bending in the modes.

Fig. 4 presents the variation of modal SDC's and natural frequencies of a $\left( \pm 45^{\circ}\right)$ cross-ply laminate at room temperature with respect to the FVR. The modal SDC's vary more uniformly with the FVR than with the ply angle. A switching occurs between modes 3 and 4. This reduction of modal SDC's as the FVR increases was expected [1].

The temperature effect on the modal SDC's and natural frequencies of the $0.50 \mathrm{FVR}$ $\left( \pm 45^{\circ}\right)$ cantilever beam is illustrated in Fig. 5 . The temperature significantly affects the modal SDC's but has small effect on the natural frequencies.

\section{Cantilever Plate}

Fig. 6 shows the variation of modal SDC's and natural frequencies with respect to the ply angle. Mode 1 is the 1st out-of-plane bending along the $\mathrm{x}$-axis coupled with some bending in the $\mathrm{y}$-direction, and mode 2 is mostly the 1st torsional modal shape. Mode 3 is initially the 1st out-of-plane bending in the $y$-direction, then as the ply angle increases is gradually coupled with the $2 \mathrm{nd}$ out-of-plane bending mode in $\mathrm{x}$-direction, and near $90^{\circ}$ is mostly the $2 \mathrm{nd}$ bending in $\mathrm{x}$-direction. The 4 th mode is mostly the 2 nd torsional shape near $0^{\circ}$, switches gradually to a coupled out-of-plane bending mode in $\mathrm{x}$ and $\mathrm{y}$-directions, and then switches to the 2nd torsional shape. As seen in Fig. 6, the modal SDC's follow more or less continuous variations with the ply angle. Again, the modal SDC's follow the opposite trend of the natural frequencies. In contrast to the beam, the plate is a twodimensional structure and its modes are mostly coupled changing shapes gradually. The 
only exemption is mode 4 near $70^{\circ}$. The coupled mode shapes have resulted in different variations of the modal SDC's than in the previous case of the beam. The modal SDC's of the plate do not follow closely the trends of laminate damping in bending and torsion. Furthermore, the results illustrate the importance of the aspect ratio on modal damping. The curves in Figs. 3 and 6 suggest that specimens of low aspect ratios may yield lower experimental damping values for angle-ply composites and laminates. The same figures also demonstrate that measured modal damping values depend on structure type and should be properly interpreted.

Fig. 7 presents the variation of modal SDC's and natural frequencies of the $\pm 45^{\circ}$ plate with respect to the FVR. The modal SDC's of the plate decrease faster than the respective SDC's of the beam in Fig. 3, and resemble more the variation of the longitudinal on-axis damping of unidirectional composites. The fact that the structural damping of the plate appears more fiber controlled than in the case of the beam has been attributed to the two-dimensional nature of the plate.

The effect of temperature on the modal SDC's and natural frequencies is shown in Fig. 8. The modal SDC's are more sensitive to temperature variations than the natural frequencies. Both SDC's and natural frequencies of the plate are less sensitive to temperature than the SDC's and natural frequencies of the beam. This is in agreement with the previous observation that the modal SDC's of the plate appear more fiber controlled than the modal SDC's of the beam.

\section{Cylindrical Shell}

Compared to the previous beam and plate, the cylindrical shell panel in Fig. 2c incorporates additional structural coupling between flexural and membrane deflections. As a result, the cylindrical composite shell has the more complicated mode shapes of the three structures considered in this study. Fig. 9 shows the variation of modal SDC's and natural frequencies vs. the ply angle. All modal SDC's have high values at $0^{\circ}$ and decrease continuously as the fiber angle is increasing. This type of variation is substantially different than the SDC's of the beam and plate. The structural membrane-flexure coupling and the 
coupled mode shapes are in part responsible for this type of behavior.

At $0^{\circ}$, mode 1 is an opening mode, then is coupled with the 1 st torsional shape as a result of increased material coupling between flexure and torsion, and for angles greater than $50^{\circ}$ becomes mostly the 1 st torsional modal shape. Mode 2 follows the opposite pattern. Interestingly, the SDC of the torsional modal shape is not increasing for ply angles higher than 45 degrees and follows the SDC of the opening mode. Modes 3 and 4 follow almost a similar pattern. Near $0^{\circ}$ they are respectively the 2 nd opening and 2 nd torsional modal shapes, then they appear coupled and switch shapes near $15^{\circ}$, and switch again near $55^{\circ}$. In general, the modal SDC's of the shell follow different variations with the ply angle than the previous two plane composite structures. The results illustrate the significant effect which curvature may have on the structural damping and dynamic response.

Typical variations of modal SDC's and natural frequencies with respect to the FVR are shown in Fig. 10. All modal SDC's decrease rapidly at low FVR's and then decrease slowly. For FVR's of practical interest, the modal SDC's show small sensitivity to FVR. The temperature effect on modal SDC's and natural frequencies is shown in Fig. 11. As in the case of the plate, the modal SDC's increase with temperature. The natural frequencies decrease slowly as the temperature increases and remain mostly insensitive to the temperature variation.

\section{CONCLUSIONS}

An integrated methodology was developed for the computational simulation of structural damping in beam/plate/shell type composite structures. The method incorporates micromechanics and laminate theories for composite damping, and can model the effect of constituent material parameters, temperature, moisture, general laminate configurations, and structural geometry. The structural damping simulation is based on finite element analysis and a specialty finite element was developed for this purpose. The method has been encoded into an in-house structural-analysis research computer code. 
Correlations with limited available experimental data, illustrated the accuracy of the method. The modal SDC's of a composite beam, a composite plate, and a composite shell panel were simulated. Parametric studies illustrated the sensitivity of modal structural damping to the fiber volume ratio, ply angles, temperature, and structural shape. The obtained results lead to the following conclusions:

i. The structural damping has shown significant dependence on structural configuration. Each modal SDC has also shown great dependence on the shape of the respective mode. The damping of beam-type structural components is most sensitive to variations of fiber volume ratio, fiber orientation, and temperature, while the damping of shell-type components the least.

ii. In case of simple composite structural components (beams), the 1st modal SDC follows the trend of the flexural laminate SDC, but the SDC's of the higher modes have shown a pattern of rapid variations near double natural frequencies. In more complicated composite structures (plates and shells), the pattern of rapid switchings was less predominant, however, unpredictability in modal SDC's was induced as a result of coupled mode shapes. Hence, structural analysis is recommended for reliable predictions of structural damping and proper measured data interpretation.

iii. The aspect ratio has a significant effect on the modal SDC's of composite plane structures (beams or plates). The effect was more significant for higher modes. Geometric curvature has also a significant effect on composite structural damping. The results illustrate that the aspect ratio and warping of specimens may significantly affect the accuracy of experimental damping measurements in off-axis composite laminates, especially in higher modes.

iv. Ply angles were found to be the most important parameters affecting the modal damping of composite structures. Significant alterations in the dynamic response may occur by tailoring the ply angles. The effect of fiber volume ratio on modal SDC's was less important.

v. The temperature had also a significant effect on structural modal damping. In all 
structural cases, structural damping was more sensitive than the natural frequencies to temperature variations.

Overall, the application examples demonstrated the versatility of the current method in the dynamic analysis of composite structures. Proper tailoring of the basic composite materials, lamination, and structural shape may significantly improve the damped dynamic response of composite structures. The results also suggest that the tailoring of composite structures for improved damped dynamic performance would be a complicated task and may be best accomplished by combining the methodology described herein with formal optimization methods.

\section{ACKNOWLEDGEMENT}

This work was performed while the author held a National Research Council - NASA Research Associateship.

\section{REFERENCES}

1. Saravanos D. A. and Chamis C. C. "Unified Micromechanics of Damping for Unidirectional Fiber Composites," NASA TM-102107, (1989). (Also, Journal of Composites Technology and Research, Spring 1990).

2. Saravanos D. A. and Chamis C. C. "Mechanics of Damping for Fiber Composite Laminates Including Hygro-Thermal Effects," 30th AIAA Structures, Structural Dynamics, and Materials Conference, Paper No. 89-1191-CP, Mobile, Alabama, (1989). (Also, AIAA Journal, Aug. 1990).

3. Murthy P. L. N. and Chamis C. C. "ICAN: Integrated Composite Analyzer," AIAA Paper 84-0974, (1984).

4. Hashin Z. "Complex Moduli of Viscoelastic Composites - II. Fiber Reinforced Composite Materials," International Journal of Solids and Structures, 6:797-807 (1970).

5. Adams R. D., Fox M. A. O., Flood R. J. L., Friend R. J. and Hewitt R. L. "The Dynamic Properties of Unidirectional Carbon and Glass Fiber-Reinforced Plastics in Torsion and Flexure," Journal of Composite Materials, 3:594-603 (1969). 
6. Chang S. and Bert C. W. "Analysis of Damping for Filamentary Composite Materials," Composite Materials in Engineering Design, American Society for Metals, Metals Park, 51-62 (1973).

7. Gibson R. F. and Plunkett R. "Dynamic Mechanical Behavior of Fiber-Reinforced Composites: Measurement and Analysis," Journal of Composite Materials, 10:325341 (1976).

8. Sun C. T., Chaturvedi S. K. and Gibson R. F. "Internal Damping of Short-Fiber Reinforced Polymer Matrix Composites," Computers and Structures, 20(1-3):391-400 (1985).

9. Suarez S. A., Gibson R. F., Sun C. T. and Chaturvedi S. K. "The Influence of Fiber Length and Fiber Orientation on Damping and Stiffness of Polymer Composite Materials," Experimental Mechanics, 26(2):175-184 (1986).

10. Schultz A. B. and Tsai S. W. "Measurement of Complex Dynamic Moduli for Laminated Fiber-Reinforced Composites," Journal of Composite Materials, 3:434-443 (1969).

11. Adams R. D. and Bacon D. G. C. "Effect of Fibre Orientation and Laminated Geometry on the Dynamic Properties of CFRP," Journal of Composite Materials, 7:402-428 (1973).

12. Siu C. C. and Bert C. W. "Sinusoidal Response of Composite-Material Plates with Material Damping," ASME Journal of Engineering for Industry, 603-610 (1974).

13. Cawley P. and Adams R. D. "The Predicted and Experimental Natural Modes of Free-Free CFRP Plates," Journal of Composite Materials, 12:336-347 (1978).

14. Lin D. X., Ni R. G., and Adams R. D. "Prediction and Measurement of the Vibration Damping Parameters of Carbon and Glass Fibre-Reinforced Plastic Plates," Journal of Composite Materials, 18:132-152 (1984).

15. Chamis, C. C., Lark R. F. and Sinclair J. H., "Integrated Theory for Predicting the Hygrothermomechanical Response of Advanced Composite Structural Components," Advanced Composite Materials - Environmental Effects, ASTM STP-658, American 
Society for Testing and Materials, 160-192 (1978).

16. Ni R. G. and Adams R. D. "The Damping and Dynamic Moduli of Symmetric Laminated Composite Beams - Theoretical and Experimental Results," Journal of Composite Materials, 18:104-121 (1984).

Table 1. Mechanical properties of HM-S/epoxy system.

\begin{tabular}{lll}
\hline \hline Epoxy & HM-S Graphite & $50 \%$ HM-S/Epoxy(ref. [16]) \\
\hline$E_{m}=0.500 \mathrm{Mpsi}$ & $E_{f 11}=55.0 \mathrm{Mpsi}$ & $\psi_{l 11}=0.45 \%$ \\
$G_{m}=\begin{array}{c}(3.45 \mathrm{GPa}) \\
0.185 \mathrm{Mpsi}\end{array}$ & $\left.E_{f 22}=0.9 \mathrm{GPa}\right)$ & $\psi_{l 22}=4.22 \%$ \\
$(1.27 \mathrm{GPa})$ & $(6.2 \mathrm{GPa})$ & \\
$\psi_{m n}=10.30 \%$ & $G_{f 12}=1.1 \mathrm{Mpsi}$ & $\psi_{l 12}=7.05 \%$ \\
& & \\
$\psi_{m s}=11.75 \%$ & $\left.\nu_{f 12}=0.6 \mathrm{GPa}\right)$ & \\
& $\psi_{f 11}=0.4 \%$ & \\
& $\psi_{f 22}=0.4 \%$ & \\
& $\psi_{f 12}=0.4 \%$ & \\
\hline
\end{tabular}




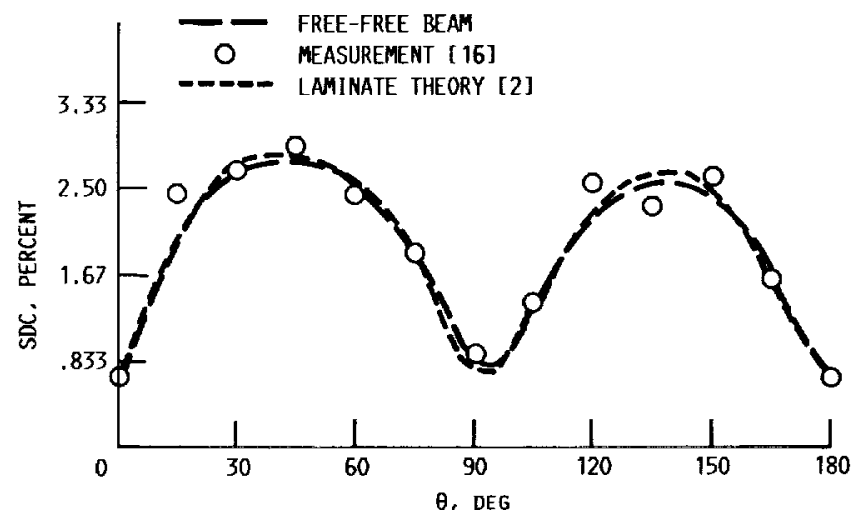

FIGURE 1. - FIRST MODAL SDC OF THE $0.50 \mathrm{FVR}(\theta / 90+\theta / 45+$ $\theta /-45+\theta)_{S}$ HM-S/EPOXY BEAM IN FREE-FREE SUPPORT.

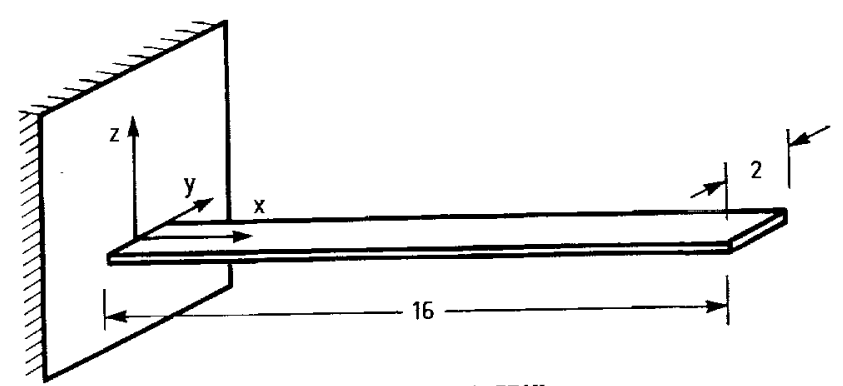

(a) CANTILEVER BEAM.

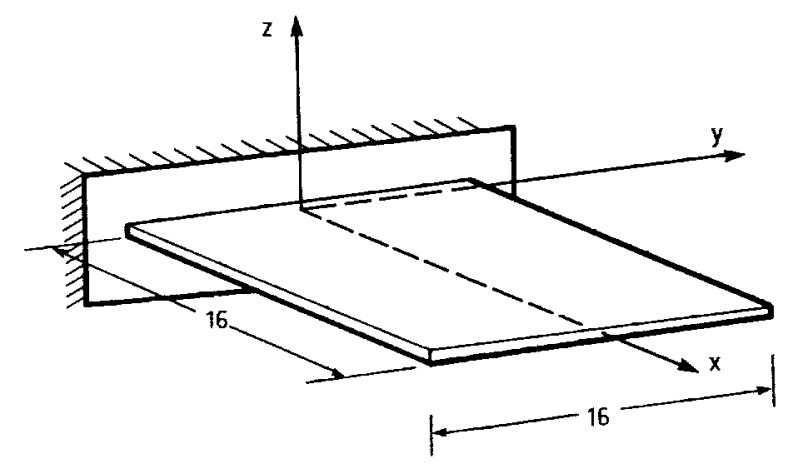

(b) CANTILEVER PLATE.

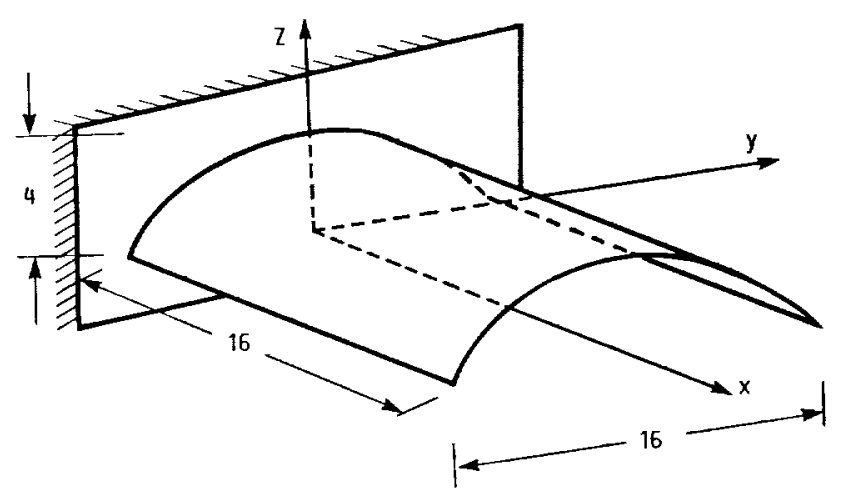

(c) CANTILEVER SHELL.

FIGURE 2. - THE THREE COMPOSITES STRUCTURES. 

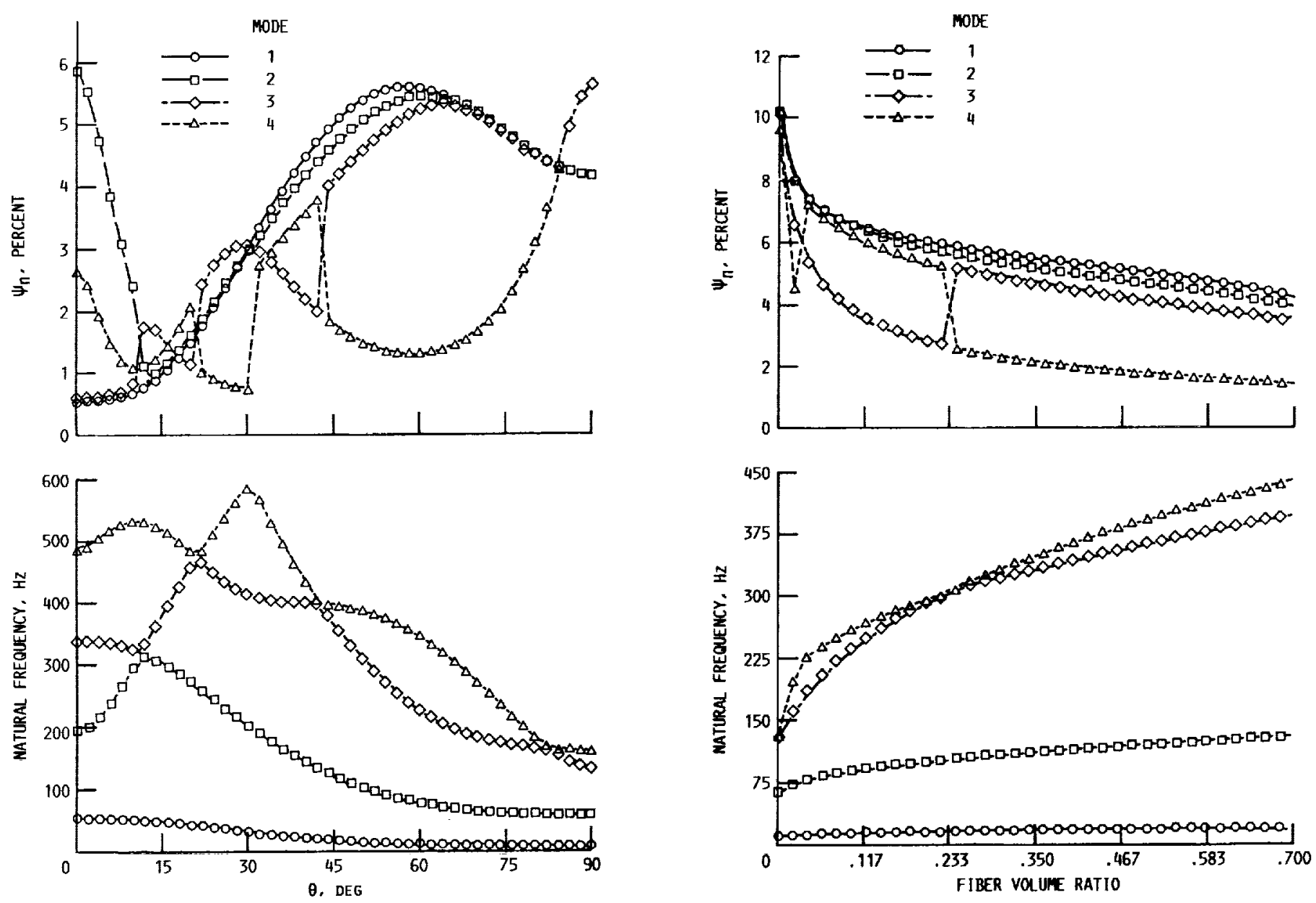

FIGURE 3. - EFFECT OF PLY ANGLE $\theta$ ON THE MODAL PROPERTIES OF THE HAM-S/EPOXY BEAM. (FVR $=0.50, T=70^{\circ} \mathrm{F}$ ).

FIGURE 4. - EFFECT OF FVR ON THE MODAL PROPERTIES OF THE HAN-S/EPOXY BEAM. $\left(\theta= \pm 45^{\circ}, T=70^{\circ} \mathrm{F}\right)$. 

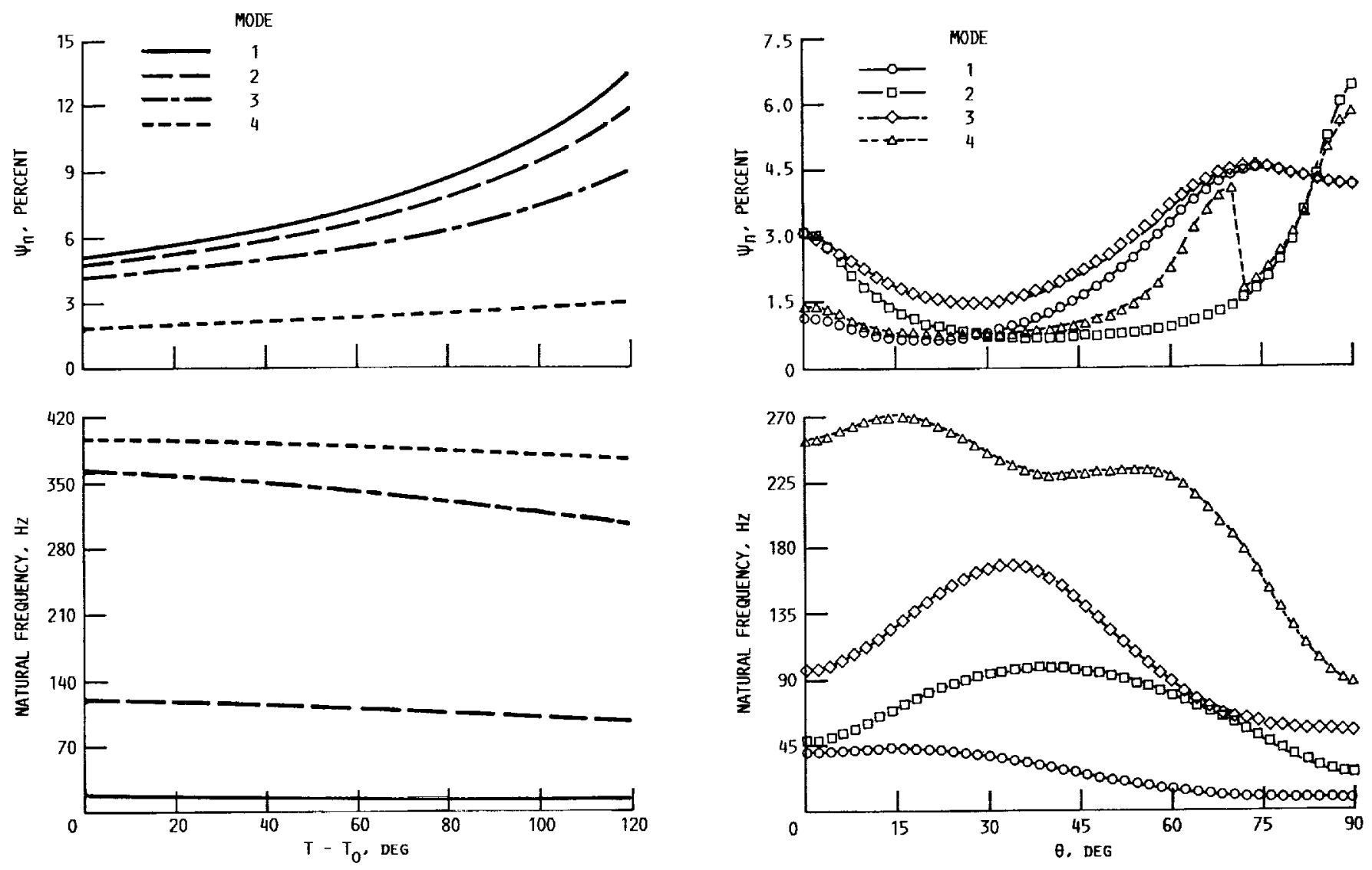

FIGURE 5. - EFFECT OF TEMPERATURE ON THE MODAL PROPERTIES OF THE HM-S/EPOXY BEAM. (FVR $\left.=0.50, \theta= \pm 45^{0}\right)$.

FIGURE 6, - EFFECT OF PLY ANGLE $\theta$ ON THE MODAL PROPERTIES OF THE HM-S/EPOXY PLATE. (FVR $=0.50 . T=70^{\circ} \mathrm{F}$ ). 

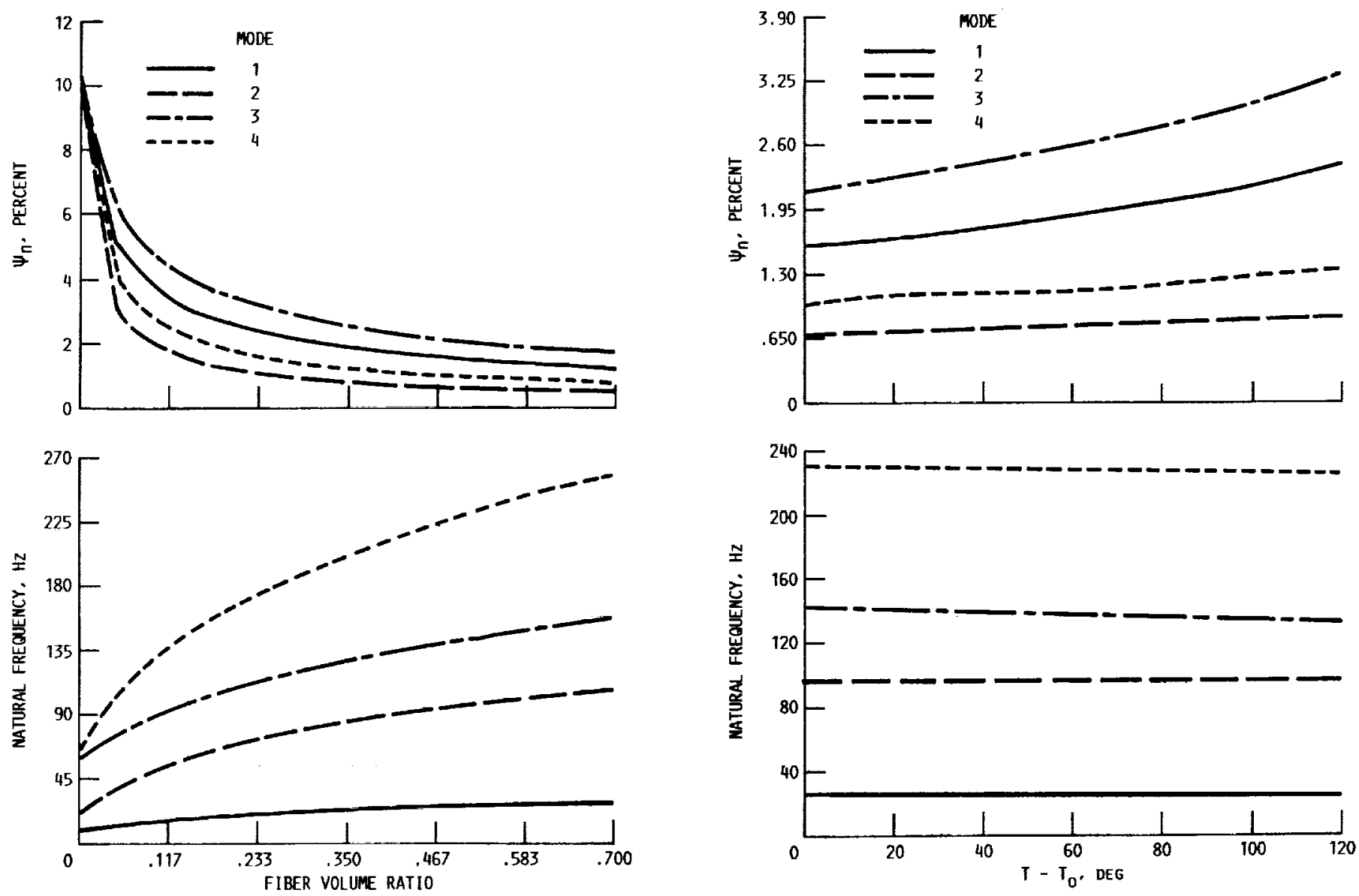

FIGURE 7. - EFFECT OF FVR ON THE MODAL PROPERTIES OF THE HM-S/EPOXY PLATE, $\quad\left(\theta= \pm 45^{\circ}, T=70^{\circ} \mathrm{F}\right)$.

FIGURE 8. - EFFECT OF TEMPERATURE ON THE MODAL PROPERTIES OF THE HM-S/EPOXY PLATE. (FVR $=0.50, \theta= \pm 45^{\circ}$ ). 

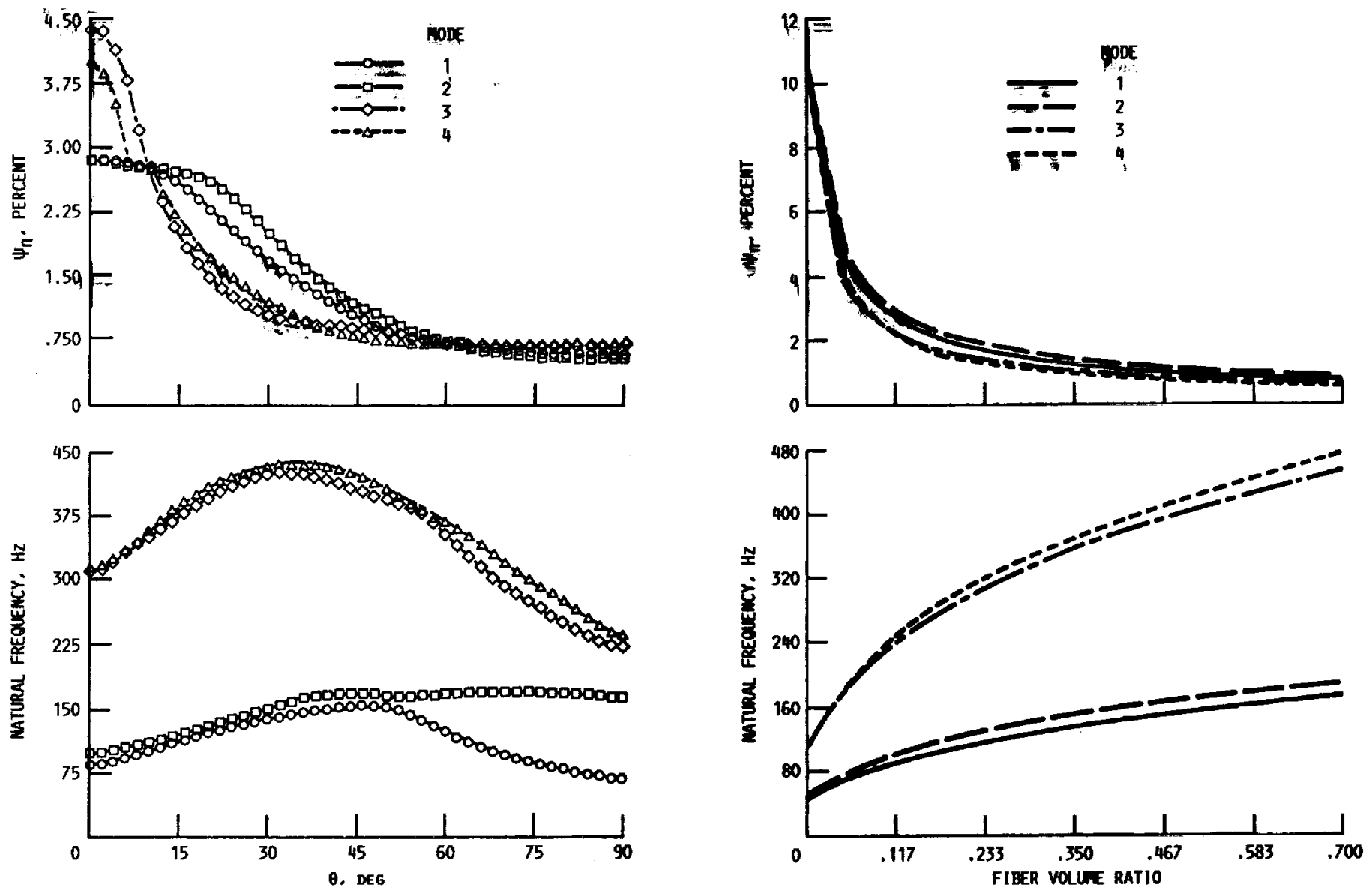

FIGURE 9. - EFFECT OF PLY AMGLE $\theta$ ON THE MODAL PROPERTIES OF THE HT-S/EPOXY SHELL. (FVR $=0.50, T=70^{\circ} \mathrm{F}$ ).

FIGURE 10. - EFFECT OF FVR ON THE MODAL PROPERTIES OF THE INTS/EPOXY SHELL. $\left(\theta= \pm 45^{\circ}, T=70^{\circ} \mathrm{F}\right)$. 

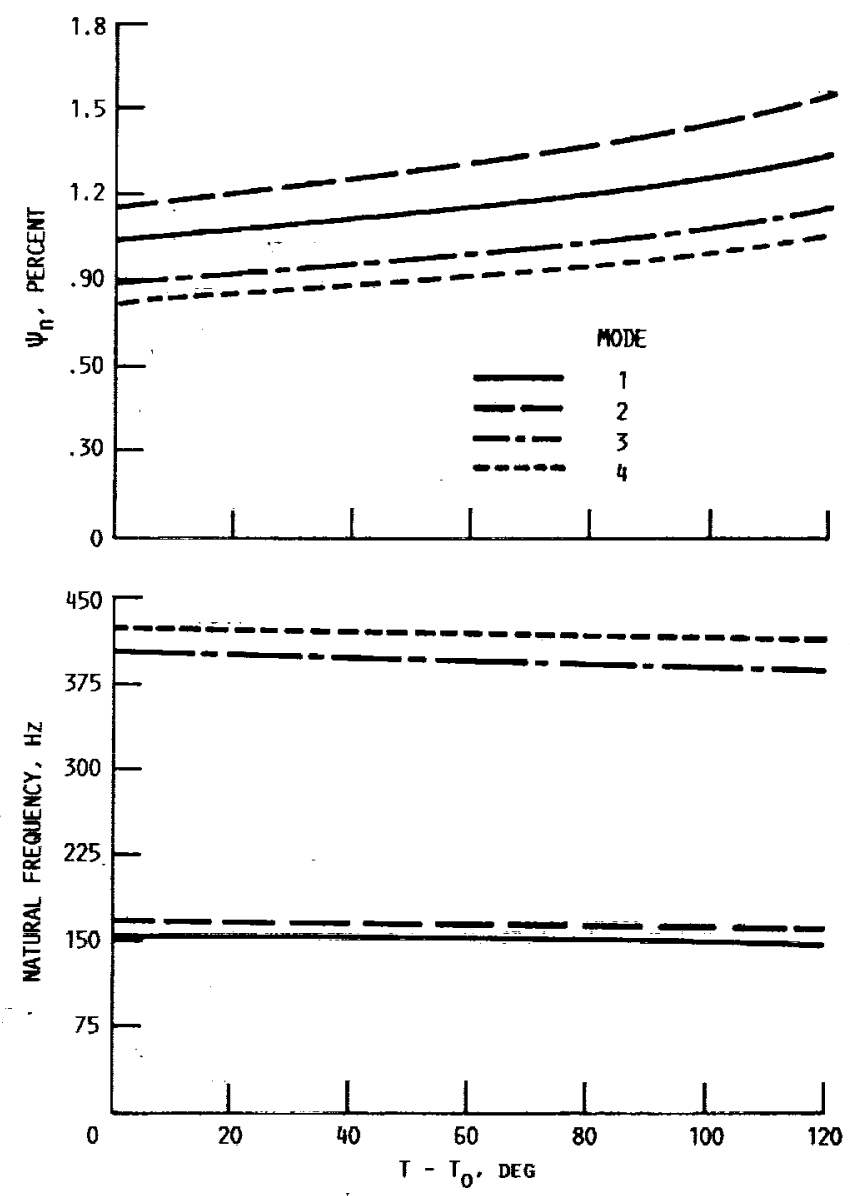

FIGURE 11. - EFFECT OF TEMPERATURE ON THE MODAL PROPERTIES OF THE HM-S/EPOXY SHELL. (FVR $=0.50, \theta= \pm 45^{\circ}$ ), 


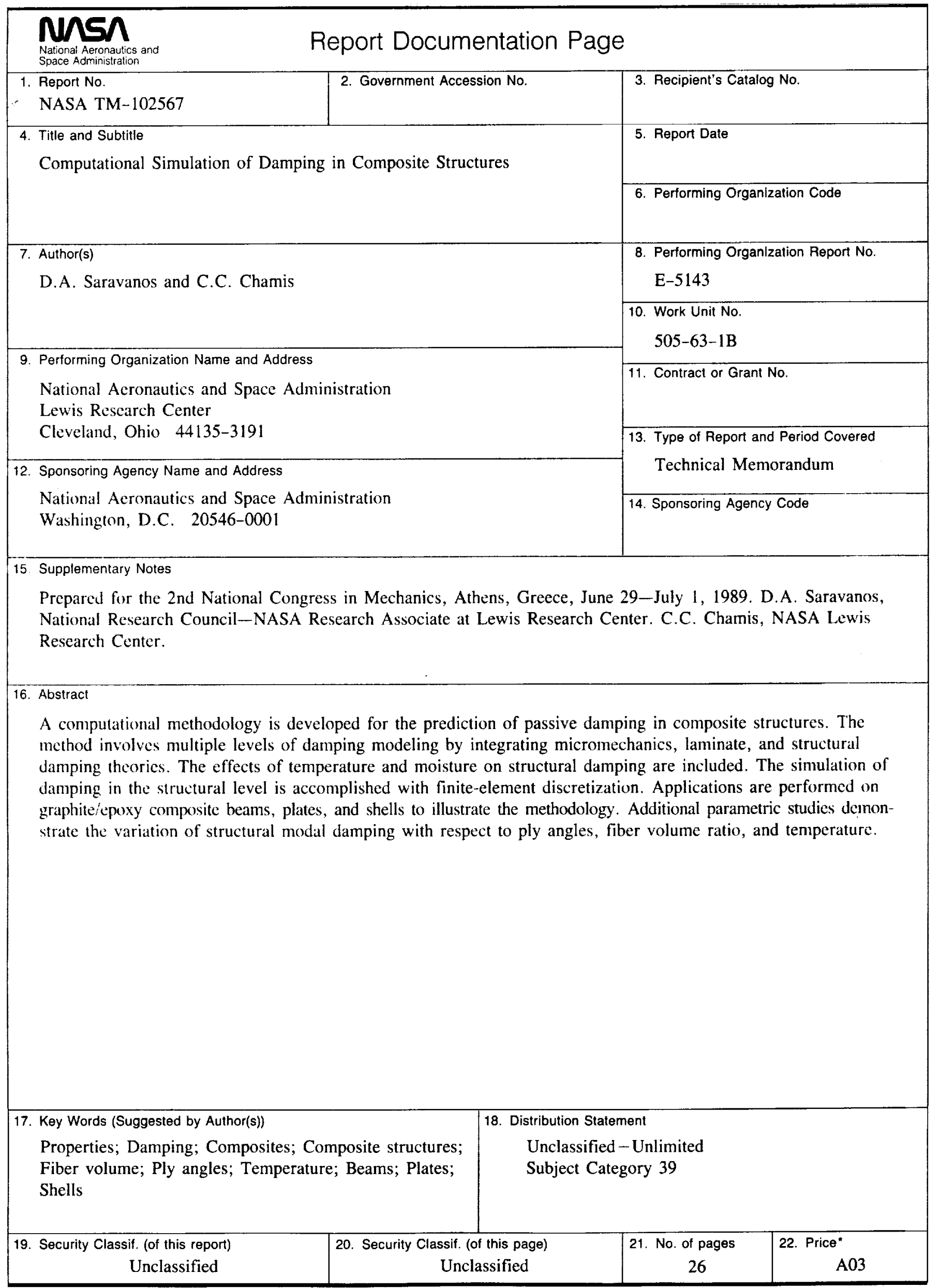




\section{.}

